Revista de Estudios Histórico-Jurídicos

[Sección Historia de los Derechos Patrios de América]

XXXV (Valparaíso, Chile, 2013)

[pp. $461-479$ ]

\title{
LA APLICACIÓN DEL FUERO MILITAR A LA POBLACIÓN MiLiCiana en El Río de la Plata
}

[The Application of the Military Privileges to the Militia in Rio de La Plata]

\author{
EMILIO FABIÁn HARARI* \\ Universidad de Buenos Aires, República Argentina
}

\begin{abstract}
RESUMEN AвSTRACT
As a legacy of Derecho Indiano, at Río
de la Plata the military privileges were ap-
plied for cases alien to the military services
until 1823. It was thought to judge the line
infantry veterans, but military courts had
to judge actions of civilians performing
voluntary services, organized in provincial
militia. Therefore, the magistrates applied
the military Law by using the faculty of the
judicial arbitrator. This article deals with
how the military privileges apply to indi-
viduals that do not belong to the institution
but that provide temporary services to it.
KEYwORDs
Militia of Rio de la Plata - Military
privileges - Military courts.

Como herencia del Derecho indiano, en el Río de la Plata se aplicó el fuero militar para causas ajenas al servicio castrense hasta 1823. Pensada para impartir justicia a los veteranos del ejército de línea, los tribunales militares debieron, no obstante, juzgar comportamientos de la población civil en servicio voluntario, organizada en milicias provinciales. En consecuencia, los magistrados aplicaron el Derecho militar utilizando la facultad del arbitrio judicial. Este artículo investiga la forma que el fuero militar se aplica a individuos que no pertenecen a la corporación, pero que prestan circunstancial servicio.

Palabras clave

Milicias del Río de la Plata - Fuero militar - Tribunales militares.
\end{abstract}

ReCiBIDO el 23 de noviembre de 2012 y ACEPTADO el 20 de mayo de 2013

* Doctor en Historia por la Universidad de Buenos Aires. Profesor de la Facultad de Filosofía y Letras de la Universidad de Buenos Aires. Correo electrónico: harari@live.com.ar 


\section{INTRODUCCIÓN}

En la República Argentina, la sanción del Código de Justicia Militar, en 1895, puso fin a un sistema de leyes heredado del antiguo régimen, principalmente integrado por las “Ordenanzas de Carlos III" (1768) y el Reglamento de milicias (1801), al que se le superpusieron algunas disposiciones gubernamentales, bandos militares y usos y costumbres propios de nuevas realidades provocadas por las guerras y la aparición de gobiernos locales ${ }^{1}$.

Durante el régimen hispánico, predominó en América un sistema de reclutamiento mixto: junto con un ejército profesional (de línea) convivían una serie de regimientos milicianos ${ }^{2}$. Cada vecino o domiciliado estaba obligado a prestar servicio de armas a su ciudad en caso de emergencia. Para garantizar la eficiencia de estos cuerpos, los voluntarios debían acudir a instrucciones semanales, a cargo de oficiales profesionales ${ }^{3}$.

Las guerras de independencia, a las que se sumaron las internas y las que enfrentaron a estados americanos, provocaron en el continente, durante el siglo XIX, un estado de alerta militar y la extensión de la condición castrense a gran parte de la población masculina adulta ${ }^{4}$. Junto con el ejército profesional, también se multiplicaron los elementos milicianos, que llegaron incluso a abarcar población no libre ${ }^{5}$. Por consiguiente, los magistrados ordinarios vieron sustraer de su fuero a una importante parte de la sociedad -que era reclutada para defender su nación o su provincia (según el caso) - y la justicia militar se encontró interviniendo en una cantidad mayor de causas ${ }^{6}$.

${ }^{1}$ Zaffaroni, Eugenio Raúl - Cavallero, Ricardo Juan. Derecho penal militar: lineamientos de la parte general (Buenos Aires, Ariel, 1980), pp. 34-55.

${ }^{2}$ Marchena Fernández, Juan, Oficiales y soldados en el ejército de América (Sevilla, Escuela de Estudios Hispano Americanos de Sevilla, 1983), p. 83.

${ }^{3}$ Cansanello, Oreste Carlos, De súbditos a ciudadanos. Ensayo sobre las libertades en los orígenes republicanos. Buenos Aires 1810-1852 (Buenos Aires, Ediciones Imago Mundi, 2003), pp. 53-55.

${ }^{4}$ Halperín Donghi, Tulio, Historia de América Latina contemporánea (14a edición, Buenos Aires, Siglo XXI, 1996), cap. $2^{\circ}$.; Chust, Manuel - Marchena FernÁndeZ, Juan (compiladores), Las armas de la nación Iberoamericana (Madrid, Editorial Iberoamericana, 2007), 2a Parte: "Los ciudadanos en armas".

${ }^{5}$ Santoni, Pedro, A Fear of the People: The Civic Militia of Mexico in 1845, en The Hispanic American Historical Review, 2 (1988), p. 68; y KuETHE, Allan, The Status of the Free Pardo in the Disciplined Militia of New Granada, en The Journal of Negro History, 2 (1971), p. 56. Para el Río de la Plata, véanse: MORRONE, Francisco, Los negros en el ejército: declinación demográfica y disolución (Buenos Aires, Centro Editor de América Latina, 1996); RibÓN, Victoria, La participación de la población de origen africano en los ejércitos revolucionarios en el Río de la Plata. Nuevas estrategias y formas de resistencia, 1800-1820 (tesis de licenciatura en Historia, inédita, Buenos Aires, Facultad de Filosofía y Letras, Universidad de Buenos Aires, 2001). Para otras regiones como Cuyo y Salta véase: MAllo, Silvia - Telesca, Ignacio (directores), "Negros de la Patria". Los afro-descendientes en las luchas por la independencia en el antiguo Virreinato del Río de la Plata (Buenos Aires, SB, 2010).

${ }^{6}$ AвÁsolo, Ezequiel: El Derecho penal militar en la historia argentina (Córdoba, Academia Nacional de Derecho y Ciencias Sociales de Córdoba, 2002), p. 174. 
En el Río de la Plata, esa ampliación de la militarización comenzó antes de la aparición del primer gobierno local. En 1806, una invasión marítima y terrestre por parte de Gran Bretaña obligó a la población de la ciudad y la campaña bonaerense a armarse en regimientos voluntarios ${ }^{7}$. Esos regimientos se mantuvieron activos hasta 1810 y luego fueron reconvertidos bajo la denominación de civicos $^{8}$. En este trabajo, abordaremos la forma en que se aplicó el fuero militar para estos individuos que, sustraídos a la justicia ordinaria, no terminaban de formar parte del elenco militar estable, desde la formación de los cuerpos milicianos estables (1806) hasta la abolición del fuero militar en Buenos Aires, en $1823^{9}$.

\section{Las Características del fuero militar en el Derecho Castellano}

La denominación "fuero" remite al lugar donde se pronuncian los juicios: “jurisdicción o potestad de juzgar”, según Alejandro Bacardí10. El fuero podía ser ordinario o especial. Bacardí define a este último como "reunión o agregado de los privilegios que se conceden a cierta clase de personas" e implicaba un privilegio especial que permitía sustraer las causas a la justicia ordinaria y al individuo ser juzgado por sus pares. Dentro de los fueros especiales, existían los fueros reales o profesionales, que se circunscribían a las causas vinculadas con el ejercicio de su profesión, y los estrictamente personales, que abarcaban todos los asuntos en que estuviera implicado el titular ${ }^{11}$.

Los diferentes fueros debían definirse según una serie de variables: si es real o personal, las materias que abarca (civil y criminal), si es activo y pasivo y si ampara sólo al titular (personalísimo) o también a sus familiares y criados $^{12}$. La segmentación de la justicia en diferentes fueros especiales tenía como premisa la idea de que ciertos hombres sólo podían ser juzgados por sus pares. En realidad, se trataba de la expresión de una sociedad basada en el privilegio, en donde el concepto de isonomía, en términos universales, aún no había sido implementado.

El fuero militar tiene su origen remoto en el período visigótico. La tiufadía, institución de origen germano, era la organización militar al mando del tiufado, quien era al propio tiempo juez de sus soldados en tiempos de guerra y de paz ${ }^{13}$.

\footnotetext{
${ }^{7}$ Para un estudio pormenorizado, véanse: HALPERÍN DONGHI, Tulio, Militarización revolucionaria en Buenos Aires, 1806-1815, ahora, en Él mismo (compilador), El ocaso del orden colonial en Hispanoamérica (Buenos Aires, Sudamericana, 1978); RoBerTs, Carlos: Las invasiones inglesas ( $3^{\circ}$ edición, Buenos Aires, Emecé, 2000); y Harari, Fabián, Hacendados en armas. El Cuerpo de Patricios, de las Invasiones Inglesas a la Revolución (1806-1810) (Buenos Aires, Ediciones RYR, 2009).

${ }^{8}$ Di Meglio, Gabriel, ;Viva el bajo pueblo! La plebe urbana de Buenos Aires y la política entre la Revolución de Mayo y el rosismo (Buenos Aires, Prometeo, 2006), pp. 136-143.

${ }^{9}$ DíAz, Benito, La igualdad ante la ley: abolición de los fueron personales (1822-1823), en Trabajos y Comunicaciones, 3 (1952), p. 19.

${ }^{10}$ Bacardí, Alejandro, Nuevo Colón, lib. I, tít. $1^{\circ}$ (Barcelona, Establecimiento Tipográfico Ramirez, 1857), I, p. 1.

${ }^{11}$ Levaggi, Abelardo, Los fueros especiales. Contribución al estudio de la administración de justicia en el Río de la Plata, en Revista de Historia del Derecho Rircardo Levene, 22 (1971), pp. 45-46.

${ }^{12}$ Levaggi, Los fueros especiales, cit. (n. 11), pp. 45-46.

${ }^{13}$ Meli, Rosa, Los fueros militares en el Derecho indiano (Caracas, Academia Nacional de la Historia, 1979), pp. 232-233.
} 
En los siglos XII y XIII, si bien en los pequeños reinos cristianos y en las huestes de la reconquista aparecen disposiciones dispersas basadas, éstas respondían a relaciones propias de una sociedad fronteriza que intentaban asegurar una debida prestación militar, por lo que la normativa era sumamente incompleta. Los castigos no implicaban la pérdida de la libertad y no aparecía la figura de deserción. Es recién bajo los Reyes Católicos, a fines del siglo XV, cuando la formación de contingentes permanentes produce la aparición de un derecho militar con un espacio normativo propio. En los siglos siguientes, las guerras europeas obligaron a los Austrias a modernizar el ejército, que implicaba grandes contingentes que debían tener una unidad. Esta tarea se terminó de realizar recién bajo el dominio borbónico. Sin embargo, el movimiento hacia esa modernización en los siglos XVI y XVII provocó la sanción de ordenanzas castrenses particulares y el surgimiento de juristas militares, lo que daba cuenta de cierta complejidad en el Derecho militar.

La extensión del fuero militar y la aparición de un Derecho militar desarrollado se producen bajo la administración de la dinastía borbónica. Algunos autores sostienen que estas reformas se implementaron bajo el reinado de Carlos III $^{14}$. Sin embargo, Saszdi Borja ha señalado que el intento de cierta sistematización debe remontarse al fin de la Guerra de Sucesión, a comienzos del siglo XVIII ${ }^{15}$. Efectivamente, Felipe $\mathrm{V}$ ostenta una voluntad reformista en la creación de las Ordenanzas de Flandes y la castellanización y militarización de la vida política. No obstante, la obra más importante de legislación militar, las Ordenanzas de 1768, resultan de un trabajo de recopilación iniciado en 1749. En todo caso, la extensión del ejército y su determinante peso social en la península obligan a una reglamentación mucho más minuciosa y sistemática.

¿Quiénes podían ampararse en el fuero militar? Las Ordenanzas de 1768 especifican al respecto: "Declaro que el referido fuero pertenece á todos los militares que actualmente sirven y en adelante sirvieren en mis tropas regladas, ó en empleos que subsistan con actual ejercicio en guerra, y que como tales militares gocen sueldo por mis tesorerias del ejército en campaña ó las provincias, comprendiéndose en esta clase los militares que se hubieren retirado del servicio y tuvieren despacho mio para gozar de fuero" 16 .

Ello implicaba la sustracción a la justicia ordinaria, tal como reza el artículo 5: "No podrán conocer de las causas civiles ni criminales de oficiales las justicias ordinarias, sino sólo el Capitán General, Consejo General o Comandante Militar del paraje donde residieren según la diferencia y circunstancia de los casos en la forma que se explicará más adelante" 17 .

${ }^{14}$ McAlister, Lyle, El fuero militar en la Nueva España (1764-1800) (México, Universidad Autónoma de México, 1982), cap. $5^{\circ}$.

${ }^{15}$ LeÓn-Borja, Szászdi István, El fuero militar en el ejército borbónico hispano, en Cuadernos de Historia, 15 (Córdoba, 2005), pp. 340-342.

${ }^{16}$ Ordenanzas de 1768 , t. III, trat. $8^{\circ}$, tít. $2^{\circ}$, artículo 1 , en Socías, Mariano, Ordenanzas de Su Majestad para el régimen, disciplina subordinación y servicio de sus Ejércitos (Madrid, Escuela Tipográfica de Madrid, 1865).

${ }^{17}$ Ibíd., t. III, trat. VIII, tít. $1^{\circ}$, artículo 5 . 
No podían ser llamados por la justicia por deudas contraídas en servicio a excepción de que la deuda fuera con la Real Hacienda. En el caso de que la deuda se hubiera sido contraída antes del ingreso al servicio, el militar debía responder con bienes que no sean de uso castrense ${ }^{18}$. Se proponía, además, ciertas exenciones y preeminencias: "A los oficiales y soldados que estuvieren en actual servicio no podrán las justicias de los parajes en que residieren apremiarlos á tener oficios concejiles, ni de la Cruzada, mayordomía, ni tutela contra su voluntad; gozará la excepción de pago de servicio ordinario y extraordinario, y no podrá imponérseles alojamiento, repartimiento de carros, bagajes ni bastimentos si no fueren para mi Real casa y corte, y siendo casados gozarán sus mujeres de las mismas preeminencias"19.

Es decir, los militares aforados gozaban de la capacidad de sustraerse al pago de determinados impuestos y de evitar el nombramiento de ciertos cargos. El fuero era trasladado, también, a sus mujeres. En los artículos octavo y noveno del tomo, tratado y título que estamos examinando, se señala el alcance del fuero, además de la esposa, a los hijos y a la servidumbre. En caso de muerte, la viuda y las hijas gozan del fuero hasta que tomen matrimonio. En el caso de los hijos, sólo hasta los dieciséis años. Con la extensión del fuero a los criados podemos ver que la legislación sanciona no las sujeciones personales, por las cuales ciertas condiciones de los señores se extienden a sus criados. Para el caso de los milicianos, la Ordenanza prescribía que debían someterse al fuero civil ${ }^{20}$.

El goce del fuero militar no eximía a los aforados de presentarse ante la justicia ordinaria, en caso de ser requeridos o en caso de ser imputados por ella, pero debían informar a su comandante. Sólo en caso de ser detenidos in fraganti, no se hacía indispensable avisar a su superior ${ }^{21}$.

El título $2^{\circ}$ prescribe los casos de desafuero. Entre ellos se lo somete a justicia ordinaria al que "incurriere en los delitos de resistencia formal á la justicia, ó desafío probado", también por la introducción de moneda falsa y por el robo o amancebamiento en la corte ${ }^{22}$. En el título $3^{\circ}$ señalaba los casos en el que personal civil podía ser sometido al fuero militar. Así, se reclamaba a "toda persona de cualquiera especie, sexo o calidad que sea, que contribuyere á la deserción de tropa de mi ejército, aconsejando o favoreciendo este delito, bien sea ocultando al desertor comprándole su ropa o armamento, o dándole otra de disfraz, deberá ser juzgado por la jurisdicción militar de que dependa el desertor favorecido, y siempre que ésta reclame á los reos de semejante crimen, estará obligada á entregarlos la justicia natural de que dependen"23.

También, en caso de estos delitos: "incendio de cuarteles, almacenes de boca y guerra, y edificios Reales militares, robos o vejaciones que en dichos parajes se ejecuten, trato de infidencia por espias, o en otra forma, insulto de centinelas o salvaguardias, $y$

\footnotetext{
${ }^{18}$ Ibíd., t.. III, trat. VIII, tít. $1^{\circ}$, artículo 4.

${ }^{19}$ Ibíd., t. III, trat. VIII, tít. $1^{\circ}$, artículo 3.

${ }^{20}$ Ibíd., t.. III, trat. VIII, tít. $1^{\mathrm{o}}$, artículo 7.

${ }^{21}$ Ibíd., t. III, trat. VIII, tít. $1^{\circ}$, artículo 10.

${ }^{22}$ Ibíd., t. III, trat. VIII, tít. II, artículos 2 y 3 .

${ }^{23}$ Ibíd., t. III, trat. VIII, tít. III, artículo 1.
} 
conjuración contra el comandante militar, oficiales o tropa en cualquiera modo que se intente o ejecute"24.

Como vemos, se proyectaba que la justicia militar tuviera la facultad no solamente de sustraer a la justicia ordinaria a un personal en continuo crecimiento durante el siglo XVIII, sino que incluso tenía la potestad de juzgar a miembros del cuerpo civil. Esta legislación constituyó una de las fuentes del Derecho militar en el Río de la Plata, aunque, como veremos, no la única.

El real decreto de 1793 ampliaba los casos de afuero y restringía los de desafuero. Esta disposición coincidió con el estallido de la guerra contra Francia. Las necesidades militares de la corona, al parecer, obligaban al monarca a extender los privilegios castrenses.

Además de los textos legales, el Derecho militar castellano e indiano tenía como fuente la doctrina jurídica. En particular, el trabajo de Félix Colon de Larriategui, Juzgados militares de España y sus Indias, publicado en 1787 (y que hubo de sufrir varias reediciones hasta la definitiva en 1817$)^{25}$. Esta obra se ocupaba de comentar la legislación militar en España y América, integrando, junto a las Ordenanzas, las diferentes disposiciones institucionales. Los auditores solían utilizar a este autor como autoridad a la hora de emitir dictamen ${ }^{26}$.

\section{El fuero militar en el Virreinato del Río de la Plata}

En el Río de la Plata, la importancia del contingente miliciano provocó la necesidad de establecer cierta reglamentación de su funcionamiento. Nos referimos al Reglamento de milicias de 1801. Existía, para su redacción un antecedente americano sobre este tipo de legislación: las Ordenanzas para las milicias de Cuba, de $1769^{27}$. Veamos entonces qué plantea el reglamento rioplatense con respecto al fuero militar.

En el capítulo $4^{\circ}$, artículo 1 , se señala que "todo soldado miliciano gozará del fuero militar" ${ }^{28}$. En el $9^{\circ}$, se amplía la disposición a todos los oficiales y subalternos: "Todos los coroneles, oficiales, sargentos, cabos y soldados de estos cuerpos gozarán del fuero militar civil y criminal y no podrán conocer de sus causas civiles y criminales la justicia ordinaria, ni otro juez o tribunal, sino sólo el virrey capitán general y los gobernadores militares, cada uno por lo que mira a las milicias de su jurisdicción, con apelación al capitán general' 29 .

Es decir, todo integrante de las milicias es acreedor del fuero. Nótese que, en los hechos, se está igualando la condición miliciana con la veterana. Esa tendencia

\footnotetext{
${ }^{24}$ Ibíd., t. III, trat. VIII, tít. III, artículo 4.

${ }^{25}$ Colón de Larriategui, Félix, Juzgados militares para España y sus Indias (Madrid, Imprenta de Viuda de Ibarra, 1788).

${ }^{26}$ AвÁsolo, Derecho penal militar, cit. (n. 6), p. 205.

${ }^{27}$ Reglamento para las Milicias de Infantería y Caballería de la Isla de Cuba, en SuÁreZ, Gerardo Santiago, El ordenamiento militar de Indias (Academia Nacional de Historia, Caracas, 1975).

${ }^{28}$ Reglamento para las milicias disciplinadas de infantería y caballería del Virreinato de Buenos Aires (Real Imprenta de Niños Expósitos, 1802), en Museo Saavedra, "Manuscritos”, 428.

${ }^{29}$ Ibíd., cap. IX, artículo 1.
} 
se halla explícitamente señalada en el capítulo $4^{\circ}$, artículo 7 , en el que se especifica que "los oficiales voluntarios de los cuerpos de blancos serán en todo tratados con la misma estimación que los de la tropa veterana de su clase, alternarán con ellos y gozarán plenamente de las mismas prerrogativas, excepciones y honores" ${ }^{30}$.

Esta equiparación entrañaba un conflicto ligado a la población de grupos subalternos que prestaba servicios en las milicias. Es importante aclarar que el artículo especifica que ese trato equitativo sólo correspondía a oficiales blancos. Es decir, quedaban fuera los subalternos y aquellos grupos de "castas". Estas clases, sin embargo, encontraron en el Reglamento cierto amparo. Por un lado, accedían a los beneficios del fuero militar. Por el otro, se sancionaba un artículo ciertamente innovador. Allí se señala que "los oficiales de cuerpos de pardos y morenos serán tratados con estimación. A ninguno se permitirá ultrajarlos de palabra ni obra, $y$ entre los de sus respectivas clases serán distinguidos y respetados" ${ }^{31}$. Es necesario señalar que el Reglamento no contradecía la legislación general, ya que en ningún lugar aparece la igualación de las condiciones. No se debe confundir la obligación de tratar con "estimación" y "respeto", con la equiparación de las "castas" con los "blancos". Con todo, sí es cierto que, a través del servicio, pardos y morenos debieron tener acceso a mayores derechos de los que podían llegar a obtener en la vida civil. De hecho, se especifica que en diciembre, a los pardos y morenos se les realice dos pagas para uniformes " $y$ para que siempre anden con la decencia correspondiente cuidarán los comandantes de ellos, no solo de que inviertan en este preciso objeto, sino también elegir aquellos sujetos cuyos oficios les den lo suficiente para dichos gastos" 32 .

Los mandos superiores en un principio se opusieron a la incorporación masiva de individuos provenientes de otras capas sociales, pero al final cedieron ante el prestigio que les reportaba estar al frente de un ejército numeroso. Los grupos tradicionales, vinculados con el Cabildo y con la jurisdicción ordinaria fueron los más reacios a admitir este tipo de cambios ${ }^{33}$.

Los milicianos estaban exentos de pagar carcelaje En el capítulo $9^{\circ}$, artículo 2 se prescribe ciertas preeminencias como la exención de oficios, cargos concejiles y tutelas. Si bien debían pagar los propios municipales, no se les podía exigir contribuciones para levantar tiendas, vender cualquier mercancía lícita o ejercer su oficio ${ }^{34}$. También estaban exentos de toda gabela por sus personas, sueldos y bienes muebles ${ }^{35}$. En estos artículos se reconoce que el miliciano, oficial o subalterno, ejercen una actividad por fuera del servicio. En especial, los oficiales, sobre quienes se supone una mejor condición para acceder a los "oficios". En ese sentido, en dicho artículo también se aclaraba que en caso de tener "haciendas"

\footnotetext{
${ }^{30}$ Ibíd., cap. IV, artículo 7.

${ }^{31}$ Ibíd., cap. IV, artículo 11.

${ }^{32}$ Ibíd., cap. II, artículo 20.

${ }^{33}$ Levaggi, Abelardo, Díptico de historia del fuero militar, en Revista de Historia del Derecho Rircardo Levene, 28 (1991), p. 98.

${ }^{34}$ Reglamento para las milicias, cit. (n. 28), cap. II, artículo 43.

${ }^{35}$ Ibíd., cap. IV, artículo 4.
} 
debían estar sujetas a los repartimientos correspondientes ${ }^{36}$. Se trataba, al parecer, de una disposición más afecta a los elementos superiores de la milicia. Sin embargo, también se previene sobre la carga impositiva que se le deberá hacer al personal en servicio: "En los repartimientos generales de los pueblos o en los encabezamientos se atenderá a no recargar a los oficiales y demás individuos de la milicia, pues además de la calidad de vecinos, que los iguala con los otros para la equidad, se aumenta la más estimable de hallarse empleados en el distinguido servicio de las armas. En cualquiera ocasión que sobre esto se justificare exceso, se tomará seria providencia con el juez repartidor $u$ otra persona que contribuyere a este artículo o que teniendo jurisdicción para remediarlo no lo hiciere" ${ }^{37}$.

El Reglamento también intenta establecer un límite a la utilización del poder político sobre el personal miliciano, al establecer que "los gobernadores, sus tenientes y otros jefes no podrán emplear milicianos en comisión alguna sin evidente urgencia del servicio, a excepción del auxilio a la justicia. En caso de emplearse, deberá ser en el mismo pueblo y no por más de dos horas. Para todo otro caso deberán dar cuenta al Capitán General y harán socorrer al soldado con dos reales diarios y con tres al cabo y cuatro al sargento" 38 .

Se intentaba eliminar la arbitrariedad de la autoridad política sobre la milicia. Una práctica que el artículo parece reconocer, aunque las proscribe. No es extraño que, en algunos casos, se utilizase a personal subalterno para tareas que no correspondían a la condición militar. Vale la pena, en todo caso, preguntarse si, efectivamente, una disposición legal alcanzó para suprimirla. Los milicianos no sólo estaban exentos de ciertos impuestos y cargas, sino que gozaban del beneficio de ser atendidos en los hospitales, siempre que estuvieran sujetos a sueldo y servicio ${ }^{39}$.

Si bien, para las penas, el Reglamento remitía a la Ordenanza carolina, ciertamente severa, resguardaba a los milicianos de los abusos de sus superiores: "Se prohibe que con cualquiera pretexto puedan los cabos, sargentos y oficiales de milicias castigar con palo a los soldados. Pondrán presos a los que no cumplan con su obligación, les falten el respeto o pronta obediencia que les deben y será por los jefes del cuerpo mortificado el agresor con benignidad, pero con la debida consideración a la gravedad $y$ circunstancias de la falta" ${ }^{40}$.

El Reglamento no se ocupa de distinguir entre milicias regladas y las urbanas con respecto al fuero militar. Podría deducirse que las urbanas gozarían del fuero sólo en caso de prestar servicio. Con todo, el afuero del personal miliciano provocó una serie de resistencias importantes. Las autoridades advertían sobre dos inconvenientes. En primer lugar, la amenaza al orden social que podía representar la existencia de clases subalternas armadas en goce de privilegio. Así explicaba Pedro Cañete: "porque siendo indispensable ocupar a los artesanos y otros menestrales (que son los hombres de más razón en estos países), dejarían sus oficios y trabajos,

\footnotetext{
${ }^{36}$ Ibíd., cap. IV, artículo 4.

${ }^{37}$ Ibíd., artículo 5 .

${ }^{38}$ Ibíd., cap. II, artículo 46.

${ }^{39}$ Ibíd., cap. IV, artículo 3.

${ }^{40}$ Ibíd., cap. III, artículo 15.
} 
para andar armados; se harían holgazanes y escandalosos, y después de revolver mil pendencias con peligro de la quietud pública, al cabo no servirían sino para causar cuidados a nuestro gobierno" 41 .

En segundo, el fuero militar a la población miliciana parecía amenazar con vaciar a la justicia ordinaria. En este sentido, Vértiz alertaba al ministro José Gálvez sobre el "inconveniente de que estado alistados casi todos los hombres de cada provincia, quedaría sin autoridad la jurisdicción real ordinaria, y causaría este privilegio no poca confusión en la distribución de justicia”42. En 1799, el alcalde de primer voto, Francisco de Escalada, se quejaba al virrey a raíz de la negativa de un oficial de milicias urbanas de pardos de comparecer ante el Cabildo. Dejaba constancia de "los perjuicios e inconvenientes que pudiera acarrear una exclusiva y separación de tantos individuos de la jurisdicción real ordinaria, y además de la que experimenta con el moderno establecimiento del Consulado" ${ }^{43}$. En contraposición a estos argumentos, en La Plata, Diego de Velasco, coronel de milicias, explicaba: "no debe haber trabajo sin recompensas, que es imposible responder por la seguridad de ningún pueblo, si se carece de personas auxiliares, que lo resguarden, y que por mucha que sea mi vigilancia y esmero, sin el goce del fuero militar me será irremediable cualesquier pérdida o acontecimiento funesto. [...] pues más importa la seguridad de aquellos establecimientos que cuantos inconvenientes puedan inducirse en contradicción del fuero" ${ }^{44}$.

En el mismo sentido la Real Audiencia y los cabildos elevaron sendos reclamos para disputar ciertas competencias con la jurisdicción militar. No obstante, los virreyes sostuvieron el fuero militar en virtud de las necesidades de defensa ${ }^{45}$. Las imprecisiones normativas, en este sentido, provocaron más de una disputa entre la justicia militar, la ordinaria y la eclesiástica.

Si bien todos estos conflictos fueron reales, vale la pena preguntarse por la magnitud real de la denunciada amenaza que habría constituido el otorgamiento del fuero militar a las milicias, para el orden social o para la justicia ordinaria. En realidad, el fuero militar en sí mismo, tal como lo disponen las ordenanzas y reglamentos, no debía constituir una fuente de indisciplina. Los jueces militares, según las disposiciones legales, debían ser tan severos como los ordinarios. Más aún: las penas prescritas en las Ordenanzas carolinas resultaban ciertamente duras. Sin embargo, el Derecho no puede reducirse, y menos en este período, a lo dispuesto en las leyes. Es de suponer, y así lo señalan los principales estudios sobre el tema, que el juzgamiento por sus pares acarreaba cierta tolerancia hacia las faltas provocada por la convivencia y la necesidad de retener a los hombres en el servicio ${ }^{46}$.

${ }^{41}$ Cfr. Levaggi, Diptico, cit. (n. 33), p. 93.

42 "Oficio al Ministro José de Gálvez”, 24 de octubre de 1780, en Archivo General de la Nación [= AGN], IX, 32-6-4, exp. 1.

${ }^{43}$ AGN, IX, 19-7-8.

${ }^{44}$ AGN, "Guerra y Marina”, IX, 24-3-6, exp. 46.

${ }^{45}$ Véase Levaggi, Diptico, cit. (n. 33), pp. 111-122.

${ }^{46}$ TANZI, Héctor, La justicia militar en el Derecho indiano (con especial referencia al Río de la Plata), en Anuario de Estudios Americanos, 26 (1969), p. 275-277. 


\section{LA APLiCACión dE LAS "ORdENANZAS" \\ PARA EL CASO DE DELITOS COMETIDOS POR MILICIANOS}

La cuestión sobre quién estaba sujeto al fuero y a las Ordenanzas y, por lo tanto, la aplicación de estas últimas fue un tema ciertamente conflictivo. Cuando el jurista moderno se refiere al fuero militar, generalmente, suele unificar dos circunstancias. Por un lado, el fuero propiamente dicho, entendido como foro. Es decir, se hace alusión a la competencia de tribunales militares. Por el otro, la referencia al fuero también implica la sujeción a las leyes militares correspondientes, a las que los jueces deben atenerse. Se trata, en realidad, de dos fenómenos no necesariamente idénticos. Esa identidad -en realidad, más pretendida y teórica que real- sólo es el producto de un sistema jurídico moderno que concibe a los jueces como meros mediadores entre la ley y los individuos.

No obstante, los tribunales antiguos realizaban esta distinción. Para ilustrar el problema, comenzaremos con la cita de un dictamen de un juez fiscal, en un caso de fuga de presos, en 1818: "Vistas las declaraciones y cargos contra el civico Miguel Maciel lo hallo plenamente convencido de haber permitido la fuga del preso Juan Birrinchin, según resulta de todas las declaraciones, sin embargo de la obstinación con que se mantiene Miguel Maciel en la negativa, que es otro indicio de su culpa. Pero no sabiendo Miguel Maciel las penas de Ordenanza, y ni estando sujeto a ellas, pues es ciudadano y no veterano, dejo a la disposición de ustedes la aplicación de la pena que juzgue por conveniente" ${ }^{47}$.

Esta apreciación parece contener una paradoja: se sostiene que el acusado no está sujeto a las leyes militares, pero se lo juzga en un tribunal militar. Sin embargo, el dictamen sólo puede resultar paradojal bajo las concepciones liberales del Derecho. Si, en cambio, se tiene en cuenta que la ley no es la única fuente de justicia, puede interpretarse mejor lo que en ese momento estaba sucediendo. El acusado gozaba del fuero militar en el sentido de que debía ser juzgado por autoridades militares. Pero, por no ser veterano, el juez no podía obrar conforme a leyes que el cívico no había jurado. Para decirlo de otro modo, el tribunal no era un mero instrumento para la aplicación de leyes, sino que excedía con mucho esas funciones. No eran las leyes, sino el juez quien era competente en este caso y que, de acuerdo a la condición del reo, podía aplicar o no determinadas disposiciones. De hecho, el mismo auditor del Ejército, como asesor letrado, dictaminó la libertad de Maciel $^{48}$.

Esta distinción puede observarse en la sentencia final de un sumario instruido en 1811. Se acusa a un soldado veterano y a catorce milicianos de deserción en Tacuarí, durante la campaña al Paraguay, al mando de Manuel Belgrano. A pesar de encontrar a todos los reos culpables del mismo delito, el magistrado sentencia penas diferentes, según la condición del acusado: "Vistas y leidas todas las informaciones, cargos y confrontaciones contra Francisco Ruiz, soldado del Regimiento de Caballería de la Patria, acusado de haber desertado de este campamento, induciendo

\footnotetext{
${ }^{47}$ AGN, "Sumarios Militares", X, 30-1-2, exp. 574, f. 10.

${ }^{48}$ Ibíd., X, 30-1-2, exp. 574, f. 11.
} 
a ello a un sargento, cabo y doce milicianos, hallándose suficientemente convencido concluyo por el Rey a que sea condenado a sufrir la pena de ser pasado por las armas, señalada por S.M. en el artículo 99, tít. 10, tratado $8^{\circ}$ de sus Reales Ordenanzas y que el cabo y doce milicianos en atención a no preceder cuando se les alista filiación, ni enterarlos de ordenanzas, ni menos consta que se les haya leido los bandos del Ejército, siendo su servicio puramente de peones sin tomar armas, que sufran la pena de cuatro años a las armas en uno de los regimientos de infantería y el sargento con que confiesa que en la campaña de Portugal se le enteró de las Ordenanzas que deba servir en calidad de soldado ocho años en uno de los regimientos dichos haciéndose pública esta degradación al Ejército como lo fue el escándalo que dieron con su fuga, única culpa que aparece en ellos" ${ }^{39}$.

Otras veces, no se aplicaba las Ordenanzas por no encontrar en ellas prevista la situación particular. Así, el soldado Romero es acusado de infligir heridas a otro cívico, pero el juez fiscal se vio contrariado por el caso, a lo que agregó al entregar el sumario: "observándose en este sumario no encontrarse un solo testigo presencial del hecho, si una notable diferencia entre la declaración del herido y el llamado, no halló cómo aplicarle a Romero una pena fija según Ordenanza por lo que llevó dicho y agregarse a esto el ser la herida bastante leve y de muy pronta curación, según lo certifica el cirujano, por lo que es mi parecer concluyo por la Patria sufra la pena de dos meses de prisión en el cuartel con un grillete al servicio de él, por la embriaguez en que se conviene el ler testigo con el herido, con que estaba Romero" 50.

Es evidente que el magistrado sospechaba que Romero era culpable, pero las Ordenanzas nada advertían sobre qué hacer en esos casos. Finalmente, se lo penó por embriaguez, para lo cual no aplicó las leyes indianas.

Observemos, ahora, un caso en el que se produce un ligero intercambio sobre quiénes están sometidos a Ordenanzas. En 1821, el soldado José María Velázquez es acusado de haber dejado fugar un preso. El juez determinó que al soldado, a pesar de no ser veterano, se le había puesto de aviso que le correspondería, de castigo, las Ordenanzas. Pero, por su avanzada edad, lo condenó a cuatro meses de prisión, por ser inútil para el servicio de línea. ${ }^{51}$

El auditor, en cambio, si bien coincidió con la pena, remarcó que el soldado no estaba sujeto a Ordenanzas y afirmó: "en vista del sumario formado contra el soldado de la Legión Patricia Manuel Moreno acusado de haber dejado fugar al oficial prisionero Don José María Velázquez hallándose al centinela dice: que no pudiendo en el caso aplicarse al soldado Manuel Moreno las penas detalladas en la ordenanza a su delito, por cuanto el oficial prisionero, a quien custodiaba, no se hallaba sujeto a alguna, y no pudiendo por otra parte sentenciar al servicio de las armas como está determinado por lo avanzado de su edad, podrá VE siendo servido determinar conforme a los expuesto por el Juez Fiscal'52.

Lo que el auditor, sin decirlo expresamente, parecía sugerir, era que no bastaba leerle las Ordenanzas a un ciudadano para sujetarlo a ellas.

\footnotetext{
${ }^{49}$ Ibíd., X, 30-2-5, f. 19vta.

${ }^{50}$ Ibíd., X, 30-2-3, exp. 759, fs. 12 y12 vta.

${ }^{51}$ Ibíd., X, 30-1-3, exp. 604, f. 7 vta.

${ }^{52}$ Ibíd., X, 30-1-3, exp. 604, fs. 9vta y 10.
} 
En sus observaciones, los jueces fiscales y los auditores se remitían a la comprobación del hecho y sus eximentes, agravantes o atenuantes. Otros, sobre consideraciones más generales. En la vasta lectura de diferentes dictámenes, encontramos uno que consideramos ciertamente elocuente sobre la aplicación o no de las Ordenanzas. El proceso en cuestión es la acusación al teniente cívico del tercer tercio, Mariano Ibáñez, de haber permitido la fuga de algunos oficiales realistas. El juez fiscal Juan Vázquez Feijoo, realiza su alegato: “debiendo por este delito comprenderles la pena de los juzgados con arreglo al artículo 40 titulo 10 tratado 8 de la Ordenanza, mas el caso presente no es tan sencillo para su deliberación. Se presenta la dificultad de demostrar cuál fuese la pena de aquellos detenidos sin condena señalada, no en la clase de presos delincuentes, y cuando se hubiese llegado a este cálculo con la indudabilidad [sic], la administración de justicia para proporcionar exactamente la pena al delito, será preciso entrar también en el de la legitimidad del caso que se juzga. Ibáñez no debia estar allí, y no estaba como debia, porque estuvo cuarenta y ocho horas y por el corto número de soldados con que estaba. Es verdad que esto no lo autorizaba para permitir a los prisioneros aquella salida, pero también lo es que la Ordenanza, que prescribe pena a los delitos de los militares, detalla reglas para el servicio de ellos con precisa proporción de unos con otras y aquellos no pueden ser exactos si estas son fallidas; auméntese esta reflexión el haberse aprehendidos a tres de los fugados y cerca de tres meses y medio que ha sufrido de prisión, es de parecer el Fiscal se le considere bastante penado con este arreglo, haciéndole saber las razones que el Consejo determinó en consideración para debilitar la severidad a que se hizo acreedor; a no ser que las luces de VSS arbitren providencia más estimable" 53 .

El juez entonces plantea dos problemas. En primer lugar, los presos no estaban sentenciados y, por lo tanto, no puede considerarse estrictamente como una fuga. En segundo lugar, y he aquí lo que nos interesa, Vázquez Feijoo reconoce que el teniente no cuidó debidamente su puesto, pero alega que no se le habían proporcionado los medios para hacerlo. Los reglamentos, parece afirmar, prescriben obligaciones, pero también medios para cumplirlas a cargo del Estado, y la severidad en las primeras debe estar en proporción a los segundos. Dicho menos atenuadamente: el Estado no podía pedirle a un oficial lo que él mismo era incapaz de cumplir y los jueces no podían circunscribirse al hecho puntual, sino que debían tener en cuenta todo el contexto para poder dictar un fallo considerado justo. El Consejo de Guerra reconoció al tiempo en prisión y la captura de los prófugos como atenuante y declaró la libertad del teniente. Eso sí, no se privó de citar el artículo 22, título $6^{\circ}$ del tratado $8^{\circ}$ de las Ordenanzas, que prescribe cuestiones meramente procedimentales ${ }^{54}$.

En la campaña, podemos observar una apreciación similar. En 1817, en

${ }^{53}$ Ibíd., X, 29-11-6, exp. 473, fs. 21 y 21 vta.

54 "Si de pluralidad de votos resultare absolución se le pondrá luego al reo en libertad, y tanto de las causas cuyas sentencias haga por sí ejecutar el Consejo de Guerra de los oficiales generales, como de las que por exceptuadas deban consultárseme, remitirá a mis manos (por la de mi secretario del despacho de la Guerra) los procesos originales, con la diferencia de que las causas exceptuadas han de pasárseme los procesos sin que llegue a efectos la sentencia, y en las primeras órdenes de ejecutada, quedándose el presidente con copia del proceso", en Socías, Ordenanzas de Su Majestad, cit. (n 16), III, pp. 219-220. 
Areco (al norte de Buenos Aires, cerca de la provincia de Santa Fe), se levanta un sumario al soldado Miguel Lucero por insubordinación. Sin embargo, el Poder Ejecutivo decide su indulto. Las razones que se exponen son las siguientes: " $L a$ insubordinación porque se está procesando al soldado de milicias Miguel Lucero, consiste en algunas razones insultantes que profirió contra su capitán en circunstancias de hallarse ambos en un baile. Esta clase de crimenes reclama la disciplina militar y buen orden que sean severamente castigados, pero si se atiende a las pocas nociones que les asisten a los soldados de las milicias de campaña de lo que con esta parte exigen sus obligaciones y al roce que igualmente tienen con ellos los mismos oficiales, considero al citado Lucero acreedor a la gracia que suplica su defensor con motivo del glorioso aniversario de nuestra independencia y que se podrá mandar sobreseer la causa aplicándole a las armas por tiempo que sea del supremo agrado" 55 .

A las apreciaciones propias de la condición y de su instrucción se agrega, en este caso, factores geográficos: las condiciones de servicio en la campaña bonaerense.

Disponemos, de un caso altamente significativo para nuestro tema de estudio, en el cual se trasluce una discusión sobre la pertinencia de la aplicación de las leyes militares al personal miliciano. Los protagonistas son los dos auditores, que se ocuparon del caso, y el inspector general, que interviene en la causa. El eje del intercambio fue la aplicación de las Ordenanzas contra las penas arbitrarias a las que solían apelar los tribunales ${ }^{56}$. El caso en cuestión es el del oficial, teniente Pedro Pablo Mora, a quien se acusaba de haberse embriagado en la guardia del Hospital Militar y provocar alboroto. Mora era un capitán ciudadano, no era veterano, y no sabía leer ni escribir. Ante esto, el Auditor Pedro Somellera dictamina, el 22 de marzo de 1821: "un exceso semejante debe conceptuarse tan remarcable en la clase a que corresponde el Teniente Mora, que cree el exponente no hacer de él mención la Ordenanza ni las órdenes de 26 de octubre de 1776, 3 de junio de 1777 y otras posteriores, porque jamás ha podido presumirse un defecto semejante en los señores oficiales. La circunstancia de hallarse el teniente Mora de Comandante de una Guardia a la sazón que se embriagó debería hacer reputarlo entre aquellos que abandonan la Guardia y sujeto por lo mismo a las penas que le impone la Orden de $1^{\circ}$ de septiembre de 1776, y aunque cree el Auditor no sea aplicable a Mora todo el rigor de esta ley, ya por consideración a no corresponder a un cuerpo veterano, ya por debérsele presumir ignorar las obligaciones de su clase, como bastante lo indica la circunstancia de no saber firmar, cree, sin embargo, que no debe dejársele en la clase de oficial y que debe recogérsele los despachos y que se haga saber así en la orden como podrá VS consultarlo al Excelentísimo Señor Gobernador y capitán General' 57.

Somellera se inclinaba, entonces, por no hacer caer sobre el oficial el peso de las Ordenanzas, ya que el teniente no era un veterano y no se le había instruido en el conocimiento de las leyes penales. En definitiva, se inclinaba por la aplica-

\footnotetext{
${ }^{55}$ AGN, "Sumarios Militares", X, 30-1-1, f. 29 vta-30.

${ }^{56}$ Recordemos que el Derecho indiano preveía el uso del arbitrio judicial por parte del magistrado. Véase LeIva, Alberto, La institución del arbitrio judicial en el Río de la Plata, en Revista de Historia del Derecho Rircardo Levene, 24 (1978), pp. 93-106.

${ }^{57}$ AGN, "Sumarios Militares", X, 30-1-2, exp. 562, fs. 13vta y 14.
} 
ción de penas arbitrarias. El auditor Villegas, si bien se muestra de acuerdo con la imposibilidad de aplicar las Ordenanzas, sostiene que la pena propuesta por Somellera es, más bien, un beneficio indebido.

Ante estos planteos, el inspector general, José Rondeau, decide intervenir en la causa, en procura de establecer un criterio distinto, más apegado a la legislación: "Tratándose de prever a aplicar el remedio bastante para cortar los abusos que en lo sucesivo pueda introducir la impunidad en esta clase de milicia y a fin que los castigos que se les impongan no lleven el carácter de arbitrarios, es de parecer esta Inspección General se les sujete y juzgue por la Ordenanza del Ejército cuanto incurran en faltas del servicio, sin lo cual la seguridad de los puestos estará constantemente comprometida, pudiendo también hacerse a los jefes que componen dicha Brigada la prevención superior de reservar en las horas de Academia que han establecido para enseñar evoluciones, el tiempo necesario para instruirles en las obligaciones respectivas al servicio de la guarnición. Sobre todo VE resolverá lo que su superior discernimiento conceptúo más adaptable y ventajoso para cortar tan perjudiciales abusos" $" 58$.

Lo que Rondeau estaba solicitando era que se someta a todos los cívicos a las Ordenanzas, sean veteranos o ciudadanos, de modo de poder emplear una sola reglamentación estricta para todos los tercios, sin dar lugar a arbitrios. Para ello, los Jefes debían ocuparse de que sus oficiales conociesen la legislación. Villegas, sin embargo, advierte algo más decididamente: "Propone el Señor Inspector General para atajar las faltas del servicio en que pueden incurrir los individuos de la fuerza que no es veterana. Le parece al Auditor General Interino el que en toda previsión sería capaz de contenerlas y le aconsejaría si no saltase luego un inconveniente de mucha gravedad, tal es que esa milicia no ha contratado la observancia de la Ordenanza, no disfruta de sus privilegios, ni goza prest o su equivalente en vestuario y entretenimiento o socorro, que con la comida declaró suplirla el Congreso Nacional de 818 para la imposición de las leyes penales. Al exponente le parece podría adaptarse uno de dos temperamentos. El primero, que hiciera a los Jefes de la Brigada la prevención que propone el Señor Inspector General, pero con la declaración que serían juzgados en el Tribunal del Señor Gobernador los oficiales infractores en el servicio de la plaza, según la cualidad, tiempo y circunstancia de sus excesos, es decir, a penas arbitrarias, pero severas y seguras. El otro, que los destacamentos de las guardias que requieren un oficial de comandante o por el honor del lugar o importancia se den a oficiales veteranos y los otros a sargentos, buscándose siempre los de mejor conducta, pero en la misma línea de veteranos de uno u otro modo, el mejor servicio, no se hacen novedades en la Ordenanza y VE puede obrar por sí cuando en el otro caso sería necesaria la sanción de la Honorable Junta Provincial's9.

Villegas trazaba un panorama similar al de Vázquez Feijoo, sólo que algo más crudo. En primer lugar, legalmente los tercios no eran tropas de línea. En segundo, no eran tratados por el Estado como tales, a pesar de tener derecho al prest y al socorro. No podía pedírseles, por lo tanto, obediencia, cuando no se les concedía los derechos correspondientes. Villegas parece admitir, subrepticiamente, que las

${ }^{58}$ Ibíd., X, 30-1-2, exp. 562, fs. 16 y 16 vta.
${ }^{59}$ Ibíd., X, 30-1-2, exp. 562, fs. 17 y 17 vta. 
penas arbitrarias podían ser benignas al estipular que podían mantener los arbitrios, pero con penas "severas". También admitía que podían no cumplirse al resaltar que debían, además, ser "seguras”. Como solución el auditor ofrecía dos alternativas: disponer de penas arbitrarias más severas y avisar del cambio a los oficiales o no destinar ciudadanos a tareas que exijan cierto comportamiento y disciplina castrense. En particular, aconsejaba esta segunda alternativa ya que, advertía, para la primera hacía falta la sanción del Poder Legislativo. Con esta última indicación, Villegas deslizaba que Rondeau se había excedido en sus funciones.

A esta altura del desarrollo, vale la pena cierta aclaración: las Ordenanzas preveían la posibilidad de dictar penas arbitrarias. Por ejemplo, en el caso de desobediencia de soldados, cabos y sargentos en circunstancias de guerra o marcha, la pena prescripta era la de muerte. No obstante, se especificaba: "en cualquiera otra función del servicio, con la cadena perpetua $y$, fuera de estos casos, con pena arbitraria" ${ }^{60}$. Sin embargo, aquí no estamos ante excepciones, sino ante una regla que, por lo general, beneficia al acusado.

La hipótesis de que el fuero militar podía significar algo diferente para los milicianos aparece esbozada en el dictamen del fiscal José Gazcón, el 21 de septiembre de 1810, con motivo del reclamo que hizo Vicente Nieto por el comportamiento de dos oficiales del Cuerpo de Patricios en ocasión de la expedición para reprimir el levantamiento de La Paz. Nieto reclamaba un Consejo de Guerra para ambos oficiales por probada insubordinación en el trayecto. Se acusaba al capitán De la Fuente de consentir el robo de ganados por parte de su tropa, haber dicho que "todos los que venian de España eran unos pícaros, sarracenos, ladrones que venían a robar y vender esta América" 61 . Además había amenazado: "en caso que esto estuviese a favor de los indios, echaría culatas arriba y se pasaría a ellos" 62 .

Ante esta situación, el fiscal Gazcón alegaba que "los acusados no pueden ni deben ser juzgados en Consejo de Guerra de oficiales generales, donde no hay grado de súplica, recurso ni apelación, de cuyos legales arbitrios no alcanza el fiscal razón alguna para privarles de ellos a los oficiales urbanos comprendidos en este proceso, sujetándolos ahora a la severidad de las leyes militares, cuando no lo han estado estos cuerpos urbanos de nueva creación desde ella, sino con meras apariencias y accidentes efimeros de milicias regladas, ni son otra cosa propiamente que unos alistamientos de paisanos armados con uniformes arbitrarios y no el señalado por Real Orden a las urbanas de América" "63.

No dudamos en que en la defensa de los oficiales, ahora patriotas, por parte del fiscal, puede sospecharse el desconocimiento a la autoridad de un jefe militar ahora enemigo. Esa pudo haber sido una oculta motivación. No obstante, nada de ello figura en el dictamen. En todo caso, lo que nos interesa aquí es examinar los argumentos por los cuales el fiscal explica la excepcionalidad de estas formaciones milicianas y su particular relación con las Ordenanzas y el Reglamento de Milicias.

\footnotetext{
${ }^{60}$ Socías, Ordenanzas de Su Majestad, cit. (n. 16), III, p. 278.

${ }^{61}$ Biblioteca de Mayo (Buenos Aires, Senado de la Nación, 1961), XIV, p. 12451.

${ }^{62}$ Ibíd., p. 12451.

${ }^{63}$ Ibíd., p. 12444.
} 
Es de considerarse que el fiscal Gazcón no se refería a unos soldados voluntarios, sino a oficiales a sueldo. Vemos en este párrafo que, a pasar de la fachada exterior, según el letrado, estas milicias, en la práctica, no cumplían con las condiciones de ser regladas ni urbanas.

Esta especie de anormalidad tiene, para el fiscal una explicación en la particular coyuntura de las invasiones inglesas: "Las apuradas circunstancias en que se halló la capital de este reino después de su Reconquista para oponer al enemigo una fuerza respetable capaz de resistir su determinación de apoderarse de todo él con los refuerzos que habia pedido [...] obligarian al señor Santiago Liniers a publicar su proclama en agosto de 1806 para que se alistase el pueblo, por naciones, eligiendo éstas sus comandantes y oficiales. Este arbitrio verdaderamente nuevo y singular, produjo un noble entusiasmo y loable competencia de uniformarse a su costa, armarse e instruirse en los precisos rudimentos de fuegos y algunas evoluciones con el abandono de sus familias, agricultura, industria, artes y comercio" ${ }^{64}$.

Como advertimos anteriormente, las invasiones inglesas habían provocado una conformación militar particular que tendía a exceder lo que se conocía hasta entonces. Se trataba de una situación nueva, que exigía nuevas soluciones. Esa novedosa situación, sin embargo, se extendió más allá de la necesidad de defensa de la capital ante el invasor, según explicaba el fiscal: "En todo este tiempo y posteriores vicisitudes, todas de gravedad, no se innovó, y sigue hasta ahora el método primitivo. $Y$ aunque la Real Audiencia gobernadora mandó extraer de las reales ordenanzas del ejército y reimprimir en pequeños cuadernitos el tratado de leyes generales para que se leyese en los cuerpos, no era suficiente sin el respectivo a las obligaciones de su clase, ni el tiempo era ya apropósito para podar el árbol y que diese nuevos retoños, ni el oficial y soldado patriótico habia contraido un empeño libre y espontáneo bajo las formalidades de ordenanza, sino temporalmente, para libertar la patria amenazada y nada más" ${ }^{65}$.

Hay tres elementos que vale la pena resaltar en este párrafo. En primer lugar, que las autoridades reconocían lo irregular de la situación e intentaron encuadrar a las milicias a la disciplina regular y al conocimiento de las leyes. En segundo, que el problema no radicaba exclusivamente en el conocimiento o no de la normativa castrense, sino que también había que tomar en cuenta que no podía pedirse una disciplina propia de un ejército de línea a cuerpos cuya dinámica se alejaba de tal ideal. Eso es a lo que se refería Gazcón con "no era suficiente sin el respectivo a las obligaciones de su clase". En tercero, ese servicio no fue reglamentado ni ajustado a las leyes porque se había concebido como excepcional. Sin embargo, como ya sabemos, esa excepcionalidad se transformó en cotidiana.

El fiscal explica su parecer sobre la aplicación del las leyes penales militares: "Mi opinión es (salvo meliori) que no debe sujetárseles al riguroso juicio militar por el grave defecto de enseñanza y disciplina que no han tenido ni tienen. Es verdad que el actual excelentísimo señor virrey conducido del mejor celo por las mejoras de estos cuerpos, expidió al ingreso de su mando el plan de reforma, suprimiendo algunos y

${ }^{64}$ Ibíd., p. 12445.
${ }^{65}$ Ibíd., p. 12446. 
dando a los demás la numeración que hoy tienen en lugar de los nombres nacionales con que antes se diferenciaban, y previniendo que los que quedaban en servicio activo debian estar bajo el pie de ordenanza, pero la falta de ejemplares de éstas, ha sucumbido tan acertada disposición, como consta de las declaraciones de los oficiales en este proceso, quienes no sólo las ignoran sino que no tienen idea del Reglamento de Milicias regladas de este Virreinato de 14 de enero de $1801^{\prime \prime 66}$.

Y se pregunta: “¿Cómo pues podría castigarse severamente a un oficial de los tercios patrióticos, si jamás ha estado impuesto en las Ordenanzas para cumplirlas, y mucho menos en la multitud de reales órdenes posteriores que forman un código voluminoso, asi en las milicias como en el ejército?" ${ }^{7}$.

El resultado del dictamen es el siguiente: "Sería muy difusa esta primera parte si hubiese de aumentar aqui la multitud de razones que convencen hasta la evidencia que los oficiales de los tercios patrióticos, sin embargo de que gocen del fuero militar, no deben ser juzgados en consejo de guerra de oficiales generales" ${ }^{\prime 6}$.

Es exactamente lo que vemos en la mayoría de los juicios que examinamos: los acusados son llevados ante jueces militares. Sin embargo, a la hora de dictar sentencia sólo en muy pocas ocasiones se tienen en cuenta las Ordenanzas o el Reglamento de Milicias. Eso no quiere decir que no sigan vigentes para aquellos cuerpos para los que fueron pensados, sino que las guerras de independencia trajeron situaciones novedosas que ameritaban nuevas normas. Por el momento, no se innovó en la materia. De hecho, cuando se decidió crear un código penal militar propio, las milicias fueron suprimidas.

\section{CONCLUSIONES}

En el Río de la Plata, durante el período independiente, las leyes propias del Derecho indiano mantuvieron su vigencia, de la misma forma que el sistema de reclutamiento. No obstante, los ordenamientos castrenses habían sido pensados para ser aplicados a cuerpos de línea con personal veterano sujeto a estricta disciplina. La proliferación de cuerpos milicianos produjo una necesaria adaptación del Derecho a las nuevas condiciones. En ese sentido, los milicianos fueron sustraídos a la justicia ordinaria, tal como cualquier militar, pero no se les aplicó las leyes correspondientes. El arbitrio judicial, potestad vigente en el régimen hispánico y no contemplada en el moderno derecho, también aparece en la Justicia Militar y mantiene continuidad luego de la independencia. Los magistrados no eran meros vehículos de la ley, sino que debían contemplar las circunstancias, el medio, la condición y la situación que atravesaba la provincia para poder dictar sentencia.

\footnotetext{
${ }^{66}$ Ibíd., p. 12446.

${ }^{67}$ Ibíd., p. 12447.

${ }^{68}$ Ibíd., p. 12449.
} 


\section{BiBLIOGRAFÍA}

ABÁSOLO, Ezequiel: El Derecho penal militar en la historia argentina (Córdoba, Academia Nacional de Derecho y Ciencias Sociales de Córdoba, 2002).

BaCARDí, Alejandro, Nuevo Colón (Barcelona, Establecimiento Tipográfico Ramirez, 1857).

Cansanello, Oreste Carlos, De súbditos a ciudadanos. Ensayo sobre las libertades en los origenes republicanos. Buenos Aires 1810-1852 (Buenos Aires, Ediciones Imago Mundi, 2003).

Colón de Larriatregui, Félix, Juzgados militares para España y sus Indias (Madrid, Imprenta de Viuda de Ibarra, 1788).

Chust, Manuel - Marchena Fernández, Juan (compiladores), Las armas de la nación, Iberoamericana (Madrid, Editorial Iberoamericana, 2007).

Di Meglio, Gabriel, ;Viva el bajo pueblo! La plebe urbana de Buenos Aires y la politica entre la Revolución de Mayo y el rosismo (Buenos Aires, Prometeo, 2006).

DíAz, Benito, La igualdad ante la ley: abolición de los fueron personales (1822-1823), en Trabajos y Comunicaciones, 3 (1952).

Halperín Donghi, Historia de América Latina contemporánea (14ª edición, Buenos Aires, Siglo XXI, 1996).

Halperín Donghi, Tulio, Militarización revolucionaria en Buenos Aires. 1806-1815, en ÉL MISMO (compilador), El ocaso del orden colonial en Hispanoamérica (Buenos Aires, Sudamericana, 1978).

Harari, Fabián, Hacendados en armas. El Cuerpo de Patricios, de las invasiones inglesas a la Revolución (1806-1810) (Buenos Aires, Ediciones RYR, 2009).

KuETHE, Allan, The Status of the Free Pardo in the Disciplined Militia of New Granada, en The Journal of Negro History, 2 (1971) 56.

LeIva, Alberto, La institución del arbitrio judicial en el Río de la Plata, en Revista de Historia del Derecho Rircardo Levene, 24 (1978)

LEÓn-Borja, Szászdi István, El fuero militar en el ejército borbónico hispano, en Cuadernos de Historia, Córdoba, 15 (2005).

Levaggi, Abelardo, Diptico de historia del fuero militar, en Revista de Historia del Derecho Rircardo Levene, 28 (1991).

LeVAGgi, Abelardo, Los fueros especiales. Contribución al estudio de la administración de justicia en el Río de la Plata, en Revista de Historia del Derecho Rircardo Levene, 22 (1971).

Mallo, Silvia - Telesca, Ignacio (directores), "Negros de la Patria". Los afrodescendientes en las luchas por la independencia en el antiguo Virreinato del Río de la Plata (Buenos Aires, SB, 2010).

Marchena Fernández, Juan, Oficiales y soldados en el ejército de América (Sevilla, Escuela de Estudios Hispano Americanos de Sevilla, 1983).

McAlister, Lyle, El fuero militar en la Nueva España (1764-1800) (México, Universidad Autónoma de México, 1982).

Meli, Rosa, Los fueros militares en el Derecho indiano (Caracas, Academia Nacional de la Historia, 1979).

Morrone, Francisco, Los negros en el ejército: declinación demográfica y disolución (Buenos Aires, Centro Editor de América Latina, 1996).

RibÓn, Victoria, La participación de la población de origen africano en los ejércitos revolucionarios en el Río de la Plata. Nuevas estrategias y formas de resistencia, 1800- 
1820 (tesis de licenciatura, inédita, (Buenos Aires, Facultad de Filosofía y Letras, Universidad de Buenos Aires, 2001).

RoberTs, Carlos, Las invasiones inglesas ( 3 a edición, Buenos Aires, Emecé, 2000).

Santoni, Pedro, A Fear of the People: The Civic Militia of Mexico in 1845, en The Hispanic American Historical Review, 2 (1988).

TANZI, Héctor, La justicia militar en el Derecho indiano (con especial referencia al Río de la Plata), en Anuario de Estudios Americanos, 26 (1969).

Zaffaroni, Eugenio Raúl - Cavallero, Ricardo Juan, Derecho penal militar: lineamientos de la parte general (Buenos Aires, Ariel, 1980). 
